This paper was presented in the 4th International Conference on System Reliability and Safety (ICSRS), in Rome, Italy in November 2019. The following is a pre-print version of the paper.

Please cite this work as,

M. T. Hoq, M. Z. Habib, E. Shayesteh, N. Taylor, "Reliability Assessment of Protection Schemes for Series Compensated Transmission Lines," in 4th International Conference on System Reliability and Safety (ICSRS), Rome, Italy, 2019. 


\title{
Reliability Assessment of Protection Schemes for Series Compensated Transmission Lines
}

\author{
Md Tanbhir Hoq ${ }^{* \dagger}$ Md Zakaria Habib ${ }^{* \ddagger}$, Ebrahim Shayesteh ${ }^{* \S}$ and Nathaniel Taylor ${ }^{*}$ \\ * Division of Electromagnetic Engineering \\ School of Electrical Engineering \& Computer Science \\ KTH Royal Institute of Technology, 10044 Stockholm, Sweden \\ † hoq@kth.se, ${ }^{\ddagger}$ mzhabib@kth.se, ${ }^{\S}$ ebrahim.shayesteh@ee.kth.se, 9 taylor@kth.se
}

\begin{abstract}
Series capacitors are used in transmission lines for enhancing power transmission limit. However, they complicate the line's protection due to impedance change of the line, voltage inversion, current inversion and sub-synchronous oscillation. Distance and differential protections are used in different arrangements in transmission line protection. Often they are used together as main and backup protection. In this paper, the fault tree method is used to compare the reliability of three common transmission line protection schemes. The schemes considered here are distance (main)-distance (backup) $(Z, Z)$, differential (main)-distance (backup) $(\Delta, Z)$ and differential (main)-differential (backup) $(\Delta, \Delta)$. Fault trees are used to calculate the reliability of protection schemes in terms of both unavailability and failure rate. The analyses show that, for series compensated lines, using distance protection reduces protection system reliability. Differential protection performs best in terms of reliability despite depending entirely on communication.

Index Terms-Series Compensation, Reliability, Unavailability,
\end{abstract} Failure Rate, Distance Protection, Differential Protection

\section{INTRODUCTION}

Transmission lines are the backbone of the electric power system. One of the popular methods for increasing the power transfer limit of transmission lines is series capacitor compensation. This is accomplished by connecting a fixed capacitor in series with the transmission line. Generally, the capacitor bank is connected in one of the line terminals or the middle. The capacitive reactance of the series capacitor reduces the inductive reactance of the line, therefore reducing the line impedance and allowing more current flow.

Transmission lines are traditionally protected with distance protection schemes. Distance protection relay estimates the fault position in the line by calculating the impedance of the line from voltage and current measurement. In principle distance protection can work only with local measurement without communication between two line ends, but often is complemented by communication aided schemes. Distance protection is usually done making different zones in the protected line, Zone 1 is set around $80 \%$ of the line and the relay trips when it detects a fault in zone 1. In this way,

This work was funded through SweGRIDS, by the Swedish energy agency, ABB and Svenska kraftnät. zone 1 from relays at both ends of the line overlaps each other. When distance protection is assisted by communication channels, faults in the far end of the line are cleared using communication with the relay on the other end.

Differential protection is another popular method of the transmission line protection. Differential protection works on the principle that the current entering a line should be equal to the current exiting the line. In differential protection, relays at both ends of the transmission line communicate with each other and determine a fault condition depending on the sum of entering and exiting currents. Differential protection in the transmission line is dependent on the communication between the two ends of the line.

Comparative reliability analysis of distance and differential protection scheme for transmission lines has been shown in different previous research works [1], [2]. From redundancy point of view, two schemes for transmission line protection such as distance (main), distance (backup) $(Z, Z)$ and differential (main), distance (backup) $(\Delta, Z)$ were suggested in [3] and [4]. In [5], different protection schemes were compared from a reliability perspective, and it was shown that $(Z, Z)$ protection scheme were more reliable due to the differential protection's dependence on the communication channel.

However, unlike uncompensated transmission lines, for series compensated lines zone 1 in distance protection is reduced with increasing compensation level [6], [7]. Zone 1 reduction increases the dependency on communication for fault clearing, therefore worsening the distance protection system's reliability. In some cases, this caused transmission utilities to move towards using differential protection in series compensated lines [8], [9]. As we expect an increase of series compensation in transmission network in future, thus it is important to asses the reliability of distance and differential based protection schemes for series compensated lines. According to the author's knowledge, comparative reliability analysis of protection schemes for series compensated lines are not found in the current literature. This paper attempts to address the issue by quantifying the unavailability and failure rate of three common protection schemes in a series compensated line.

In this paper, for series compensated lines, three pro- 
tection schemes are compared in terms of reliability. The three schemes are, distance (main)- distance (backup) $(Z, Z)$, differential (main)- distance (backup) $(\Delta, Z)$, and differential (main)- differential (backup) $(\Delta, \Delta)$ schemes are tested with and without redundant communication channel for protection of series compensated transmission lines. The results are compared with the reliability of $(Z, Z),(\Delta, Z)$ and $(\Delta, \Delta)$ schemes of uncompensated lines as well. The details of the methodology are described in Section II.

\section{Methodology}

\section{A. System Configuration}

The system configuration for the reliability study is shown in Figure 1. Here $R_{1}$ is the main protection relay (communication enabled), $\mathrm{R}_{2}$ is backup protection relay (no communication), $\mathrm{C}_{\mathrm{E}}$ are positioning for an end-line capacitor, $\mathrm{CT}$ is a current transformer, VT is voltage transformer and $\mathrm{CB}$ is a circuit breaker. In this paper, the capacitor is assumed to be in Bus A. The capacitor bank is usually protected with metal oxide varistor (MOV) along with damping devices and bypass switches.

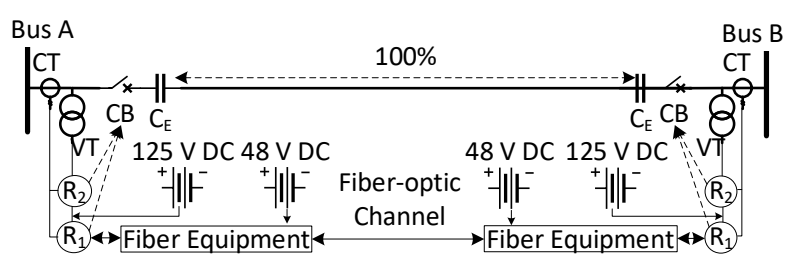

Figure 1. Transmission Line Model

\section{B. Protection Schemes}

In case of the $(Z, Z)$ scheme, relay $\mathrm{R}_{1}$ and $\mathrm{R}_{2}$ both are distance relays. In the $(\Delta, Z)$ scheme, relay $\mathrm{R}_{1}$ is a differential relay and relay $R_{2}$ is a distance relay. In the $(\Delta, \Delta)$ scheme both relays are differential. For main distance protection $\mathrm{R}_{1}$ a basic permissive overreaching transfer trip (POTT) scheme is assumed. $R_{2}$ protection in the first two cases are without any communication channels and only work with local measurements. The event of interest here is the failure of the protection scheme to clear a fault in the line in the prescribed time. The prescribed time is assumed to be 6 cycles [10]. Therefore, only high-speed protection is considered. It is assumed that the power system requires high-speed fault clearance for transient stability [10]. Therefore only highspeed protection is considered. Zone 1 protection is considered for distance relays. In uncompensated lines, distance relay zone 1 is set to $80 \%$ of the line length, the remaining $20 \%$ is cleared by communicating with the relay on the other end of the line. The relays in both buses will attempt to clear faults in their respective zone 1 but will communicate with each other in case of faults in zone 2 .

Zone 1 reach of distance relays reduces with increasing compensation level [6], [11], [12]. A reduced zone 1 implies more dependence on communication for fault clearance for distance relays. In this paper, different zone 1 reach is used to calculate the reliability of the protection schemes. For uncompensated line zone 1 is set at $80 \%$ after that zone reaches of $70 \%, 60 \%, 50 \%$, and $40 \%$ are used to represent increasing levels of compensation. Differential relays do not face such problems of zone reduction, their main issue is the sole dependence on the communication channel for protection.

\section{Scenarios}

Three protection schemes are evaluated for both compensated and uncompensated lines. Additionally, each scenario is analysed based on both dependability and security. Therefore 12 fault trees are created in total. For compensated lines, when distance relays are used, different zone reaches are used to observe the effect of compensation level on protection reliability. The method for reliability analysis is detailed in Section II-D.

\section{Reliability Analysis Method}

Fault tree method is used in analysing component failures and calculate system reliability [13]. The event of interest in a fault tree is called the top event, the failure rate of the top event is a combination of the failure rate of the underlying events. AND gate is used to express a failure caused only when all underlying equipment fail (product of failure rates), OR gate is used when a failure is caused by any failure of the underlying equipment (sum of failure rates) [10]. The reliability analysis method is adopted from [2] and [10]. The protection schemes are assessed under two criteria; failure to trip (dependability problem), and undesired trip (security problem) [10]. Two sets of fault trees are constructed for dependability and security analysis. If any protection equipment is unavailable, the protection system fails to trip for a fault. Therefore, unavailability data from components are used for dependability analysis [10]. An undesired trip usually happens when components of protection scheme fail, therefore, failure rates are used for security calculations [10]. Once the 12 fault trees are created, the effects of redundant communication channels and reducing zone 1 reach in each case can be calculated.

Figure 2 shows the fault tree for the $(Z, Z)$ scheme. The left side of the tree represents communication independence protection, for zone $1 \mathrm{R} 2$ works as a backup to R1. But, in case of communication failure, the unavailability only consists of R1. Figure 3 shows the fault tree for the $(\Delta, Z)$ scheme. For the differential relay, any unavailability in communication channel will cause the relay to fail. This is shown on the right side of the diagram. The backup distance relay R2 works as a backup for its zone 1 reach only. The capacitor bank is represented by its total unavailability. For both cases zone 1 reach can be modified to find unavailability for different compensation levels. A zone 1 setting of $80 \%$, and removing the capacitor bank unavailability will allow calculating the value for uncompensated lines. Figure 4 shows the fault tree for $(\Delta, \Delta)$ scheme. Here, two differential relays are working as main and backup protection. There is no effect of zone 


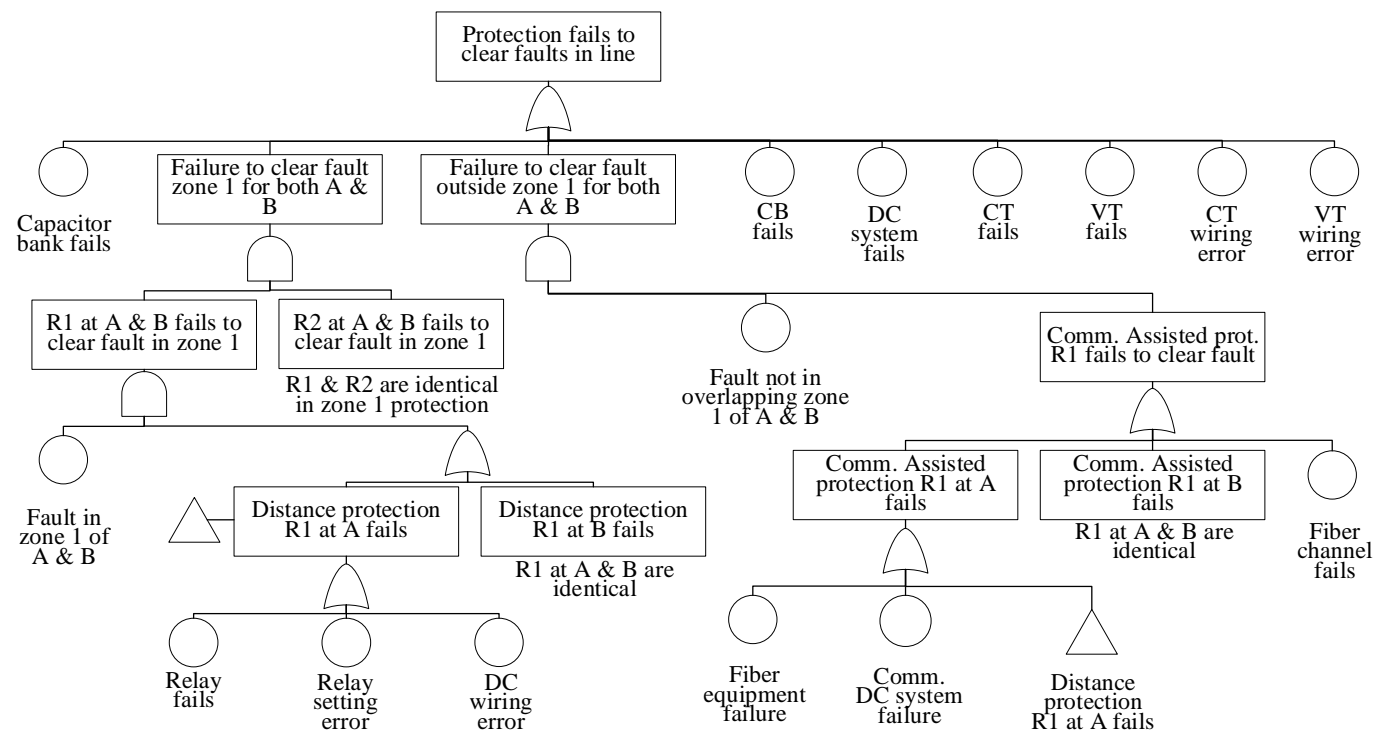

Figure 2. Dependability fault tree for $(Z, Z)$ scheme (unavailability)

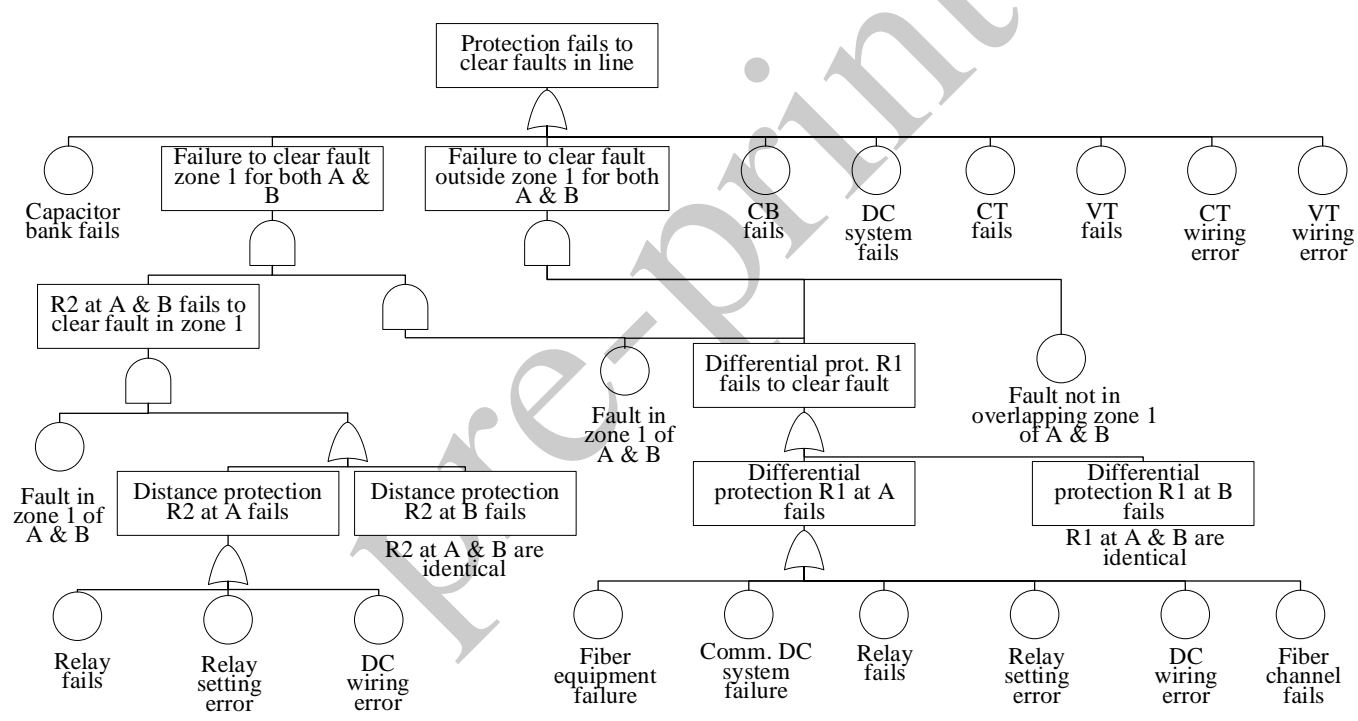

Figure 3. Dependability fault tree for $(\Delta, Z)$ scheme (unavailability)

reach in differential relays. However, they are sensitive to communication failures. In the fault tree, it is assumed that the communication channel between two line ends is nonredundant. However, the presence of communication redundancy can also be easily calculated.

The security fault tree is shown in Figure 5 for the $(\Delta, Z)$ scheme. Failure rates are used for calculating the probability of an undesired trip. The three fault trees for $(Z, Z),(\Delta, Z)$ and $(\Delta, \Delta)$ are very similar because security is calculated based on failure rates and in all schemes. Component failure introduces security problems, the same pieces of equipment are used in all cases. For example, a failure in the communication scheme will cause a false trip in both of the main distance and differential protection R1. The trees will have a somewhat different structure, but the results would be the same for all schemes. For uncompensated line, the capacitor bank can be removed to get the security result.

In practice, protection algorithms in the relays are not completely accurate in their fault detection and operation. For this analysis, relay unavailability and failure rate due to algorithm errors are discarded. The main reason for this is the lack of sufficient data for such algorithm errors. However, if such data is available, one can always add those in the fault tree presented here to see their effect. The analysis presented 


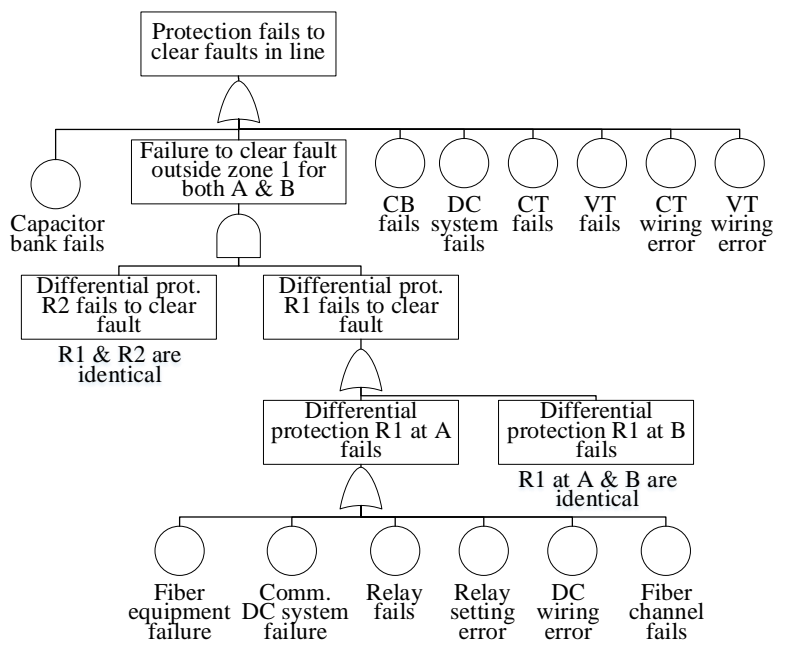

Figure 4. Dependability fault tree for $(\Delta, \Delta)$ scheme (unavailability)

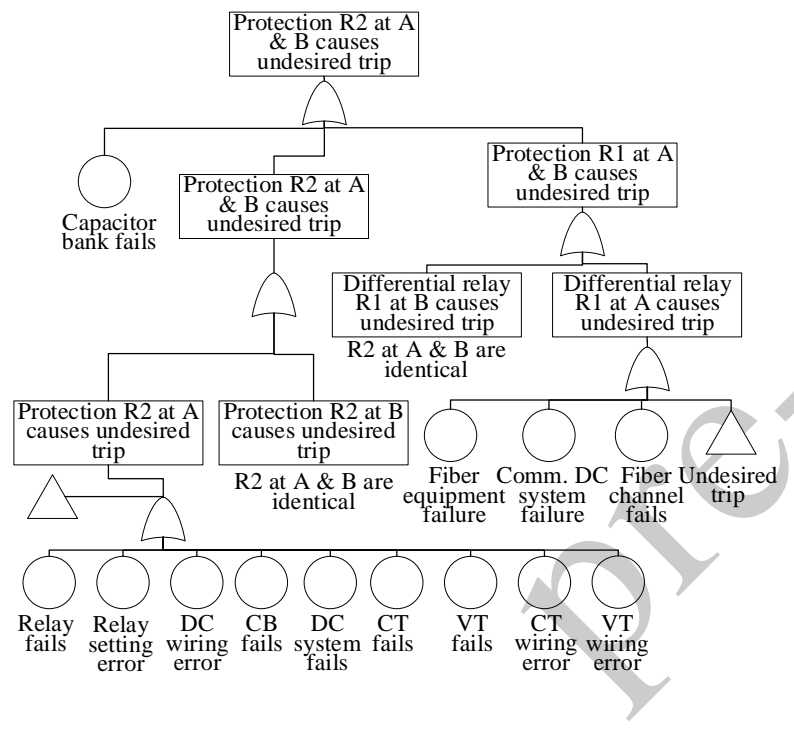

Figure 5. Security fault tree for $(\Delta, Z)$ scheme (failure rate)

here is mainly representative of hardware failures. In [14], a comprehensive reliability analysis of the complete series capacitor bank is presented, data from their analysis is used here. The capacitor bank is presented here with the cumulative unavailability and failure rate of the consisting devices as calculated in [14]. The reliability data for different equipment in the protection scheme are taken from different previous research papers [14], [10], [15]

\section{RESULTS AND DISCUSSION}

The results from the fault tree analysis are summarised in Table I. False trip (security) calculations are similar for all three schemes for reasons aforementioned in subsection II-D. The failure rate for the compensated line is higher because of the added failure rate of the capacitor bank. In Figure 2 and Figure 3, different zone values are used to calculate the unavailability (Dependability). The $(\Delta, \Delta)$ scheme is independent of the zone reach settings, therefore have the same value for all levels of zone reach. The unavailability of $(Z, Z)$ and $(\Delta, Z)$ schemes are fairly similar, with $(Z, Z)$ having slightly lower unavailability. This can be explained by the effect of zone reduction on distance relays. In both of these schemes distance relay is working as a backup. The major source of unavailability stems from the fact that the main relay R1 has to protect more portion of the line alone without any backup. That portion increases with decreasing zone 1 reach for the backup relay $\mathrm{R} 2$, increasing the overall system unavailability.

Table I

RESULTS FROM THE FAULT TREE ANALYSIS

\begin{tabular}{|c|c|c|}
\hline & Dependability & Security \\
\hline Configuration & $\begin{array}{c}\text { Unavailability } \\
(\%)\left(10^{-6}\right)\end{array}$ & $\begin{array}{l}\text { Failure Rate } \\
\text { /year }\left(10^{-6}\right)\end{array}$ \\
\hline$(Z, Z)$ Uncompensated & 1362 & 30924 \\
\hline $\begin{array}{l}(Z, Z) \text { Compensated } \\
\text { Zone } 1 \text { reach } 70 \%\end{array}$ & 2499 & \multirow{4}{*}{34071} \\
\hline $\begin{array}{l}(Z, Z) \text { Compensated } \\
\text { Zone } 1 \text { reach } 60 \%\end{array}$ & 2776 & \\
\hline $\begin{array}{l}(Z, Z) \text { Compensated } \\
\text { Zone } 1 \text { reach } 50 \%\end{array}$ & 3052 & \\
\hline $\begin{array}{l}(Z, Z) \text { Compensated } \\
\text { Zone } 1 \text { reach } 40 \%\end{array}$ & 3329 & \\
\hline$(\Delta, Z)$ Uncompensated & 1383 & 30924 \\
\hline $\begin{array}{l}(\Delta, Z) \text { Compensated } \\
\text { Zone } 1 \text { reach } 70 \%\end{array}$ & 2530 & \multirow{4}{*}{34071} \\
\hline $\begin{array}{l}(\Delta, Z) \text { Compensated } \\
\text { Zone } 1 \text { reach } 60 \%\end{array}$ & 2816 & \\
\hline $\begin{array}{l}(\Delta, Z) \text { Compensated } \\
\text { Zone } 1 \text { reach } 50 \%\end{array}$ & 3103 & \\
\hline $\begin{array}{l}(\Delta, Z) \text { Compensated } \\
\text { Zone } 1 \text { reach } 40 \%\end{array}$ & 3389 & \\
\hline ( $(\Delta, \Delta)$ Uncompensated & 812 & 30924 \\
\hline $\begin{array}{l}(\Delta, \Delta) \text { Compensated } \\
\text { All compensation levels }\end{array}$ & 1672 & 34071 \\
\hline
\end{tabular}

In practice, in the case of differential relays, as the protection is solely dependent on communication equipment, they are often provided with redundancy. The influence of redundant communication equipment on unavailability can easily be calculated from the fault trees in Figure 3, 4 and 4. The unavailability results for $(Z, Z),(\Delta, Z)$ and $(\Delta, \Delta)$ with redundant communication (RC) and single communication (SC) are shown in a bar graph Figure 6. For uncompensated lines, $(\Delta, \Delta)$ has the lower unavailability, meanwhile, the other two schemes have similar values of unavailability. As the zone reach decreases, schemes using distance protection starts having higher unavailability. Expectedly, communication redundancy improves the unavailability for all schemes compared to non-redundant communication. The gain for redundant communication is highest for $(\Delta, Z)$. For $(\Delta, \Delta)$ scheme, communication redundancy improves unavailability from $1672 \times 10^{-6}$ to $1671 \times 10^{-6}$, a very small improvement. 


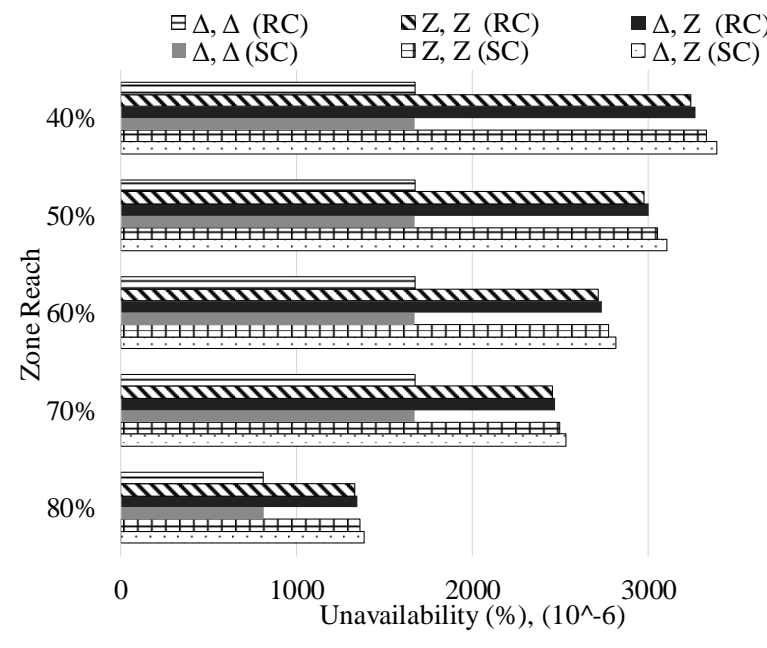

Figure 6. Unavailability results for $(Z, Z),(\Delta, Z)$ and $(\Delta, \Delta)$ scheme

One important thing to notice is the difference between the schemes using distance protection and $(\Delta, \Delta)$. As the zone reach reduces, their difference increases. This may explain different transmission system operator's inclination for using communication dependent differential protection in series compensated lines from a reliability perspective. Another thing to ponder about is that the communication channel requirement for POTT enabled distance protection is much lower than that of differential relays. Therefore, in practice, a communication channel for differential relay would be more expensive. However, it would be more reliable.

\section{CONCLUSION}

In this paper, for series compensated lines, reliability analysis of three common protection scheme are demonstrated. Differential protection is found to be the most reliable protection for series compensated lines, albeit it's communication dependency. This is due to the reduction of zone 1 in distance relays in presence of series capacitors. The increase in the level of compensation reduces the zone 1 reach of distance relays. With lower zone 1 reach, distance protection performs even worse. In general, reliability analyses are as good as the data used in the analyses. Here, data from a reputed manufacturer was used [10] to calculate the reliability parameters. However, the fault trees presented in this paper are generic and can be fed with different failure rates and unavailability data for calculating the outcomes. The fault trees can be extended for other protection schemes. In this work, configurations with only one backup protection were tested, but the fault trees can be easily modified to add and calculate the effect of more backup protection. This is one of the issues that can be addressed in future work.

\section{REFERENCES}

[1] T. Johannesson, F. Roos and S. Lindahl, 'Reliability of protection systems - operational experience 1976-2002', in 2004 Eighth IEE International Conference on Developments in Power System Protection, vol. 1, Apr. 2004, 303-306 Vol.1.

[2] E. O. Schweitzer, B. Fleming, T. J. Lee, W. Usa and P. M. Anderson, 'Reliability Analysis of Transmission Protection Using Fault Tree Methods', en, in 24th Annual Western Protective Relay Conference, Spokane, Washington, Oct. 1997, p. 18.

[3] CIGRE Working Group 34.01, 'Reliable fault clearance and back-up protection.', CIGRE, Paris, Tech. Rep., 1999.

[4] 'IEEE Recommended Practice for the Design of Reliable Industrial and Commercial Power Systems', IEEE, Standard, 2006.

[5] A. Lisnianski, D. Laredo and H. B. Haim, 'Reliability Analysis of Two Protection System Configurations for High Voltage Transmission Lines', en, in 2006 IEEE 24th Convention of Electrical \& Electronics Engineers in Israel, Eilat: IEEE, Nov. 2006, pp. 221-225.

[6] CIGRE Working Group B5.10, 'Protection, control and monitoring of series compensated networks', en, CIGRE, Paris, Tech. Rep., 2010.

[7] John Miller, Marc Brunet-Watson and Jed Leighfield, 'Review of Series Compensation for Transmission Lines', en, PSC North America, Tech. Rep., 2014, p. 65.

[8] N. Saia, 'The importance of site selection for series compensation', en, in 58th Annual Conference for Protective Relay Engineers, 2005., College Station, TX, USA: IEEE, 2005, pp. 201-210.

[9] E. Bakie, C. Westhoff, N. Fischer and J. Bell, 'Voltage and current inversion challenges when protecting seriescompensated lines - A case study', en, in 2016 69th Annual Conference for Protective Relay Engineers (CPRE), College Station, TX, USA: IEEE, Apr. 2016, pp. 1-14.

[10] E. O. Schweitzer, D. Whitehead, H. J. A. Ferrer, D. A. Tziouvaras, D. A. Costello and D. S. Escobedo, 'Line protection: Redundancy, reliability, and affordability', en, in 2011 64th Annual Conference for Protective Relay Engineers, College Station, TX: IEEE, Apr. 2011, pp. 1-24.

[11] A. P. De Oliveira and P. Da Silveira, 'Evaluation of Distance Protection Performance applied on Series Compensated Transmission Lines using Real Time Digital Simulation', en, in 2006 IEEE/PES Transmission \& Distribution Conference and Exposition: Latin America, Caracas, Venezuela: IEEE, 2006, pp. $1-6$.

[12] R. Castro and H. Pineda, 'Protection System Considerations for $400 \mathrm{kV}$ Series Compensated Transmission Lines of the Central Western Network in Venezuela', en, in 2006 IEEE/PES Transmission \& Distribution Conference and Exposition: Latin America, Caracas, Venezuela: IEEE, 2006, pp. 1-5.

[13] P. M. Anderson, Power System Protection, English, 1st edition. New York: Wiley-IEEE Press, Dec. 1998.

[14] R. M. Arias Velásquez and J. V. Mejía Lara, 'Reliability, availability and maintainability study for failure analysis in series capacitor bank', en, Engineering Failure Analysis, vol. 86, pp. 158-167, Apr. 2018.

[15] A. dos Santos, P. F. Correia and M. C. de Barros, 'Reliability and availability analysis methodology for power system protection schemes', en, in 2014 Power Systems Computation Conference, Wrocław, Poland: IEEE, Aug. 2014, pp. 1-7. 